\title{
Laser Ablation of Paint Coatings in Industry
}

\author{
Lyubomir Lazov \\ Rezekne Academy of Technology \\ Rezekne, Latvia \\ lyubomir.lazov@rta.lv \\ Imants Adijāns \\ Rezekne Academy of Technology, \\ Rezekne, Latvia \\ imants.adijans@rta.lv
}

\author{
Nikolay Angelov \\ Technical University of Gabrovo \\ Gabrovo, Bulgaria \\ angelov_np@abv.bg \\ Antons Pacejs \\ Rezekne Academy of Technology, \\ Rezekne, Latvia \\ antons.pacejs@rta.lv
}

\author{
Edmunds Teirumnieks \\ Rezekne Academy of Technology, \\ Rezekne, Latvia \\ edmunds.teirumnieks@rta.lv \\ Ērika Teirumnieka \\ Rezekne Academy of Technology, \\ Rezekne, Latvia \\ erika.teirumnieka@rta.lv
}

\begin{abstract}
A comparison is made between the laser and sandblasting methods for removing paint from industrial facilities. The advantages of laser ablation are discussed. The possibilities of laser paint removal systems - stationary and moving - are shown. The main factors influencing the laser ablation process and the indicators that determine the quality of the obtained surface are systematized. Researchers' publications on this technological process are analyzed.
\end{abstract}

Keywords - laser ablation, paint, advantages, factors, laser paint cleaning system

\section{INTRODUCTION}

Paint removal is a process that finds application in some specific areas such as maintenance of vessels, aircraft, cars and more. In industrial conditions, two main methods are used - sandblasting method and laser method. Both methods are widely used at the present stage of development of science and technology. It should be noted that the laser method is gradually expanding its position due to a number of its advantages over the sandblasting method:

\section{- $\quad$ Nature is less polluted}

The fine grits used in the sandblasting method are difficult to clean, which is too unfavorable for the environment. In the laser method, the coating is thermally removed and blown;

- $\quad$ The health of the workers is spared
The application of the sandblasting method requires strictly specialized clothing due to the strong dusting of the working environment, while the laser method uses only goggles and normal workwear.

\section{- Mobility}

The laser beam is easily delivered to the impact area, as it can be transported there by means of glass fiber.

\section{- Flexibility}

The paint can be removed without any surface damage or a surface with the necessary roughness can be obtained for easier repainting

\section{- Low cost price}

There is a lasting tendency to reduce the cost of the process. The improvement of laser sources and laser technology systems and the competition of manufacturing companies have led to a significant reduction in their market prices while expanding their capabilities. At the same time, the prices of consumables for the sandblasting method are slightly increasing.

- $\quad$ Processing of hard-to-reach places;

- $\quad$ Higher productivity;

- Easy maintenance of the laser technology system;

- $\quad$ High quality;

- Precision;

- $\quad$ Lack of direct mechanical or chemical contact with the substrate.

Laser ablation of paints is a complex process that is influenced by some basic factors. They are in complex 
relationships with each other and both the specific influence of each factor and the complex influence of the main factors must be studied [4], [20], [25 - 27].

The aim of the publication is to systematize the various techniques for the implementation of the technological process of laser ablation of paint from industrial facilities, to discuss their capabilities and to analyze the main factors influencing the process.

\section{PRESENTATION}

Laser cleaning can be defined as the removal of unwanted layers or the extended contamination of the unwanted layers from a solid substrate. In particular, laser ablation of paint from the surface of solids is an essential part of this technological process [17], [22].

Laser ablation can be viewed as a process, in which the rapidly applied heat can cause thermal expansion and propagation of a pressure shockwave, which when applied effectively can be implemented in the removal of coatings. The laser ablation process can be schematically represented as the rapid heating of the surface layers of the material undergoing ablation there by forming a plasma, which in turn creates a shockwave that ejects the ablated material outwards as fine particles (see Fig. 1). The substrate below the coating that is targeted for removal is protected from damage by keeping the laser energy density below the damage threshold. The laser ablation process is shown schematically in Figure 1 [23], [20].

(a)

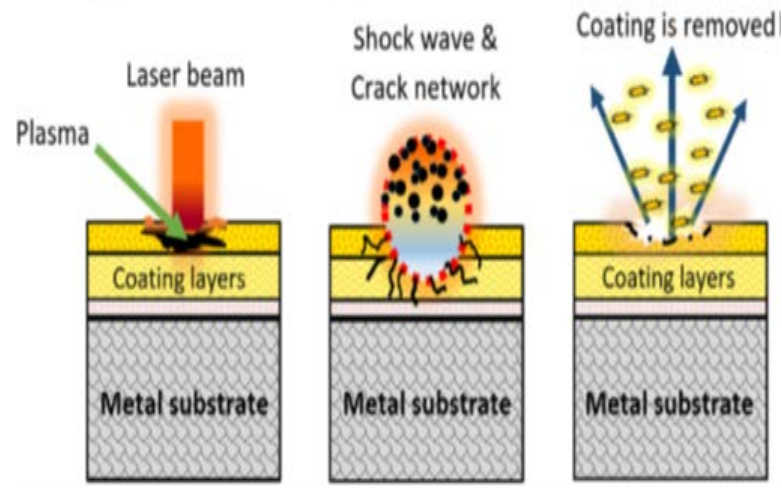

Fig. 1. Graphical illustration of the laser ablation mechanism: (a). Laser vaporizes the coating layer and creates a plasma formation. (b). Plasma creates a shock wave and crack network. (c). The top clear coat has been removed in the ablation mechanism.

In the publications of a number of authors the process of laser ablation of paint from metal surfaces is considered and researched. Various technical solutions are offered.

\section{II.1. Laser paint cleaning systems}

\section{II.1.1. Stationary laser paint cleaning systems}

An experimental system with Nd:YAG laser $(\lambda=1064$ $\mathrm{nm})$ was proposed in [18] (Fig. 2). The sample is horizontally placed on the $\mathrm{X}-\mathrm{Y}$ axis platform with the laser beam perpendicularly irradiates on it. A suction pump is used to absorb the ablated paint debris. The thickness of the paint covered on steel is $\sim 360 \mu \mathrm{m}$ and a square of 40 $\mathrm{mm} \times 40 \mathrm{~mm}$ is ablated by laser for performance evaluation of laser cleaning.

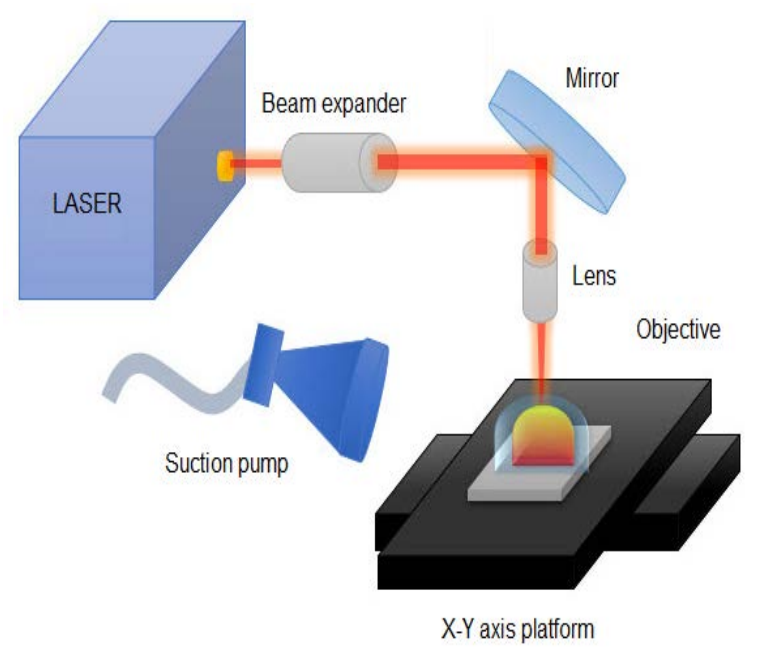

Fig. 2. Paint removal experimental setup

In the publication [10], the results are analyzed in view of the use of the system for industrial paint removal in a variety of circumstances (Fig. 3), but specifically for the use in a nuclear environment for decommissioning. The experimental work is performed using a Rofin Sinar DL025 stacked HPDL, emitting at approximately $900 \mathrm{~nm}$. The working distance used between laser optics and coating surface was around $5 \mathrm{~cm}$, with a spot size of around $12 \mathrm{~mm} \times 7 \mathrm{~mm}$. The system optics were protected by a nozzle assembly, allowing for protective air flow over the lens to prevent combustion products from depositing on the front surface.

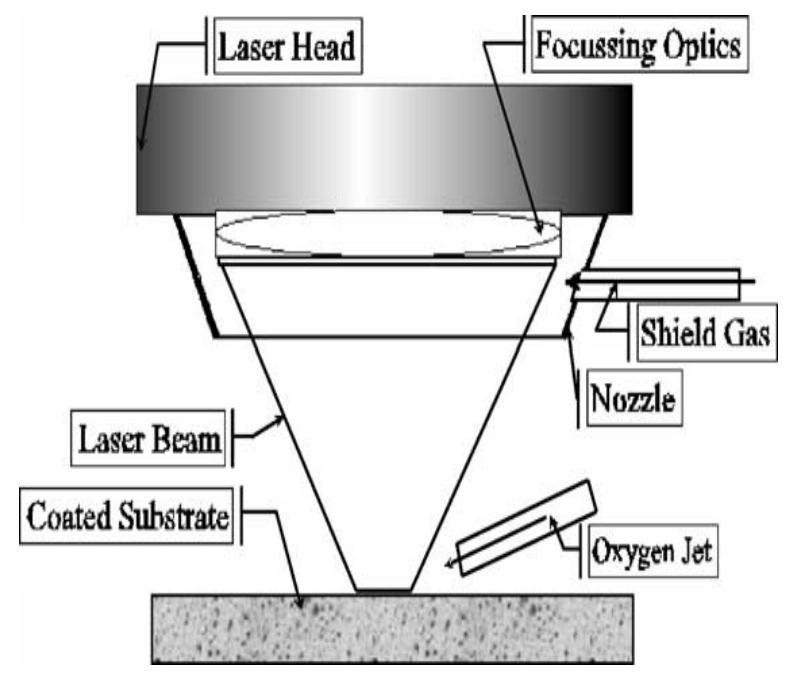

Fig. 3. Schematic of the laser-nozzle-substrate arrangement used in the experiments.

II.1.2. Moving laser paint cleaning system 
The sample surfaces in [3] are irradiated while utilizing a CW fiber laser (YLS-2000, IPG Photonics, Oxford, MA, USA) with a maximum average power of $2 \mathrm{~kW}$, wavelength of $1070 \mathrm{~nm}$. The laser beam spot is perpendicular to the substrate surface and the laser spot size is $5.0 \mathrm{~mm}$. The beam quality factor $\left(M^{2}\right)$ is 1.2 measured by a laser beam quality analyzer (SP620U). The laser head is installed on a six-axis robot arm (ABB, Zürich, Switzerland). The auxiliary device includes a water-cooled chassis for the laser and an argon canister, which serves to protect the laser head lens. Argon process gas is blown over the surface in this case, in order to minimize the combustive effects. The nozzle assembly protects the system optics that allows for protective airflow through the lens to prevent combustion products from depositing on the front surface. Figure 4 presents a schematic diagram of the experimental setup.

The laser technological system can be configured for both manual and robotic tool positioning. Figure 5 shows a standard laser system with power $400 \mathrm{~W}$ installed in a maintenance hangar at U.S. Naval Air Station, Patuxent River, MD. The gray laser cabinet connects to the handheld laser tool via a 50-meter, orange-colored fiber optic umbilical cable [24].

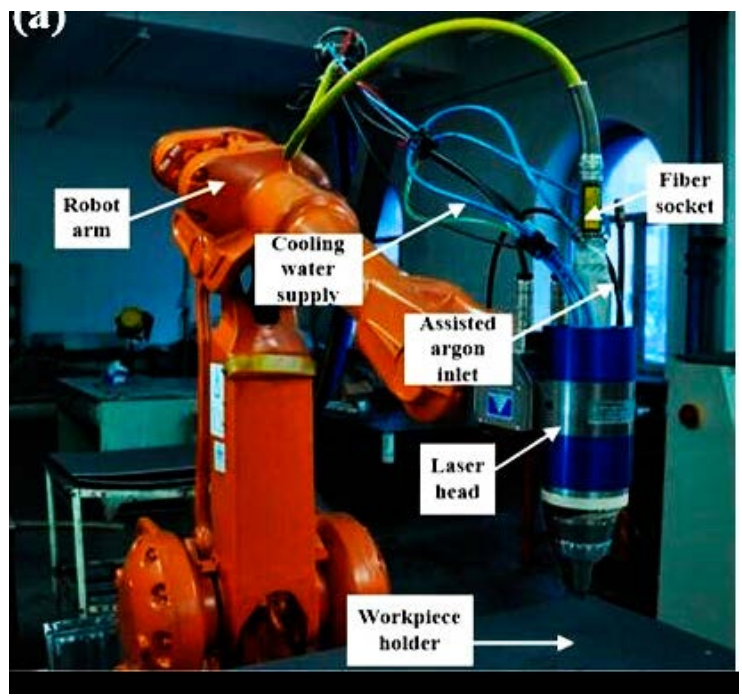

Fig. 4. Schematic diagram of experimental setup

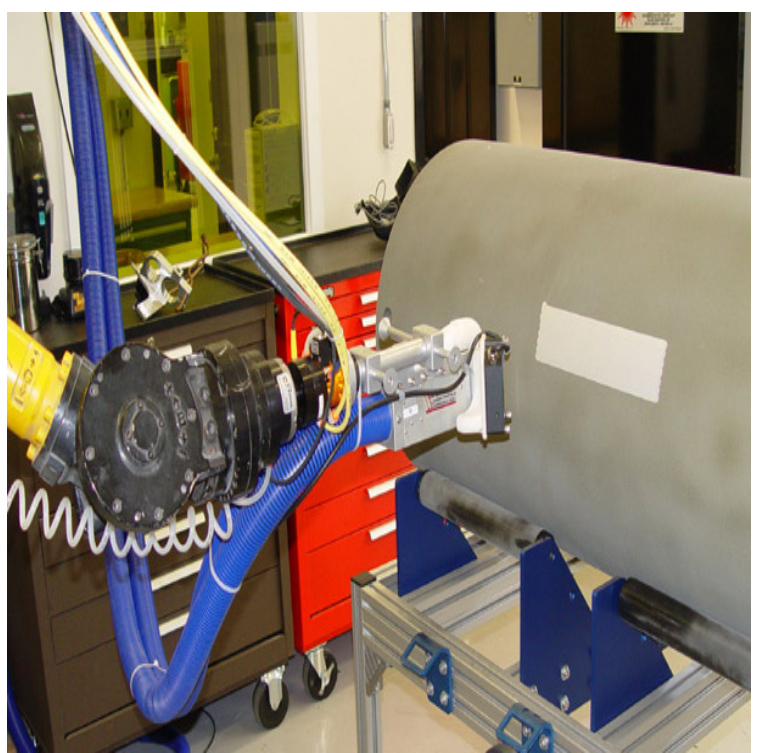

Fig. 5. A laser system in use by the US Naval Undersea Warfare Center, Keyport, WA, for cleaning test torpedoes

The manual laser tool in Figure 6 with extended fiber optic umbilical can easily reach surfaces difficult or impossible for human access. An optional video camera in the tool and heads-up operator's display enables stripping of surfaces in confined spaces, e.g., voids and tanks, or in difficult to reach spaces such as beneath or behind equipment [24].

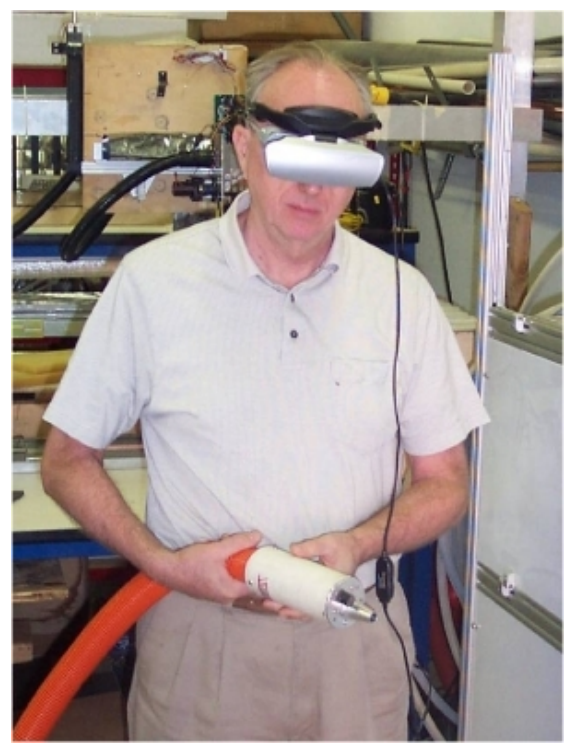

Fig. 6. Heads-up display for confined space access

The characteristics of lasers and laser paint ablation systems are presented in Table 1. It can be seen that lasers operating in both continuous and pulsed mode are used. $\mathrm{CO}_{2}$ lasers have less power than fiber lasers, Nd: YAG lasers and diode lasers, because the absorbency of dyes for radiation with a wavelength of $10.6 \mu \mathrm{m}$ (far infrared area) is greater than this for wavelength of about $1 \mu \mathrm{m}$ (near infrared area). In addition, it should be noted that the 
radiation of fiber lasers, Nd: YAG lasers and diode lasers is easily transmitted along the glass fiber to the area of impact. It is impossible to transfer $\mathrm{CO}_{2}$ laser radiation via glass fiber.

TABLE 1. SOME CHARACTERISTICS OF LASERS AND LASER SYSTEMS USED FOR LASER PAINT ABLATION

\begin{tabular}{|c|c|c|c|c|}
\hline Laser & Fiber laser & Nd:YAG laser & Diode laser & $\mathrm{CO}_{2}$ laser \\
\hline Wavelength, nm & 1064 & 1064 & $800 \div 950$ & 10600 \\
\hline Operating mode & $\begin{array}{c}\text { Pulse mode } \\
\text { CW }\end{array}$ & $\begin{array}{c}\text { Pulse mode } \\
\text { Q-switch mode } \\
\text { CW }\end{array}$ & $\begin{array}{c}\text { Pulse mode } \\
\text { CW }\end{array}$ & $\mathrm{CW}$ \\
\hline Power, W & $500 \div 2500$ & $500 \div 2500$ & $500 \div 2500$ & $100 \div 1000$ \\
\hline Diameter of work spot, mm & $1 \div 5$ & $1 \div 5$ & $1 \div 5$ & $1 \div 10$ \\
\hline Frequency, kHz & 20 & 20 & 20 & - \\
\hline Pulse duration, nm & 100 & 100 & 250 & - \\
\hline Beam quality $M^{2}$ & 1.2 & 1.5 & 10 & 6 \\
\hline Efficiency & 40 & 30 & 50 & 20 \\
\hline Possibility to transmit radiation along glass fiber & Yes & Yes & Yes & No \\
\hline
\end{tabular}

II.2. Main factors influencing the process and experimental results of their research

The main factors influencing the laser ablation process are related to the laser source (wavelength, power density, working spot diameter, pulse duration, frequency), the technological process (speed, defocusing) and the physical and chemical properties of the coating. Their reporting and research as well as taking into account the physical mechanisms in the implementation of the process will lead to high quality processing (Table 2).

A number of scientists have studied the main factors influencing the process of laser ablation of paint from metals and alloys in their publications.

The influence of power, absorbed energy, frequency and speed of scanning on the process of laser ablation of paint is studied in [18]. Technological parameter are also pulse duration $100 \mathrm{~ns}$ and diameter of work spot $100 \mu \mathrm{m}$. They are determined experimentally. The performance of the laser cleaning was evaluated. An experiment was performed with repainted coating after laser ablation. Excellent adhesion strength of $20 \mathrm{MPa}$ is achieved between the repainted coating and the substrate, which is higher than what is required by shipyard applications.

The removal of paint from the surface of metal samples using fiber lasers operating in continuous and pulsed mode was studied in [8]. They choose the specific energy as a quantity that determines the realization of the process. In cw mode the specific energy reduced with the increase of laser scan speed and corresponding increase of laser power. In case of repetitive pulsed mode the specific energy was found to depend on the pulse on-time as well as on the time interval between two successive pulses. At $1 \mathrm{kHz}$ repetition rate, the specific energy reduced with the increase of duty cycle and corresponding increase in scanning speed, but at relatively low frequencies of 50$150 \mathrm{~Hz}$ and 50\% overlap between two pulses specific energy was found to increase with increasing duty cycle. Irrespective of the mode of operation specific energy increased with the increase of average line energy. During the laser paint irradiation a plume of burning fume was formed over the surface and the variation in specific energy with laser processing parameters has been attributed to the absorption of laser radiation in the plume.

In the publication [10], the authors present work on investigating the suitability and characteristics of a $2.5 \mathrm{~kW}$ CW high power diode laser (HPDL) for the removal of chlorinated rubber (CR) and epoxy resin type paints from concrete and steel surfaces. The experimental dependence of the removal rate on the output laser power for coverage from chlorinated rubber (CR) paint, is obtained. Process characteristics, safety issues, as well as costing issues and various practical matters are discussed. 
Environment. Technology. Resources. Rezekne, Latvia Proceedings of the $13^{\text {th }}$ International Scientific and Practical Conference. Volume 3, 187-194

TABLE 2. REALIZATION OF THE PROCESS OF LASER ABLATION OF PAINT

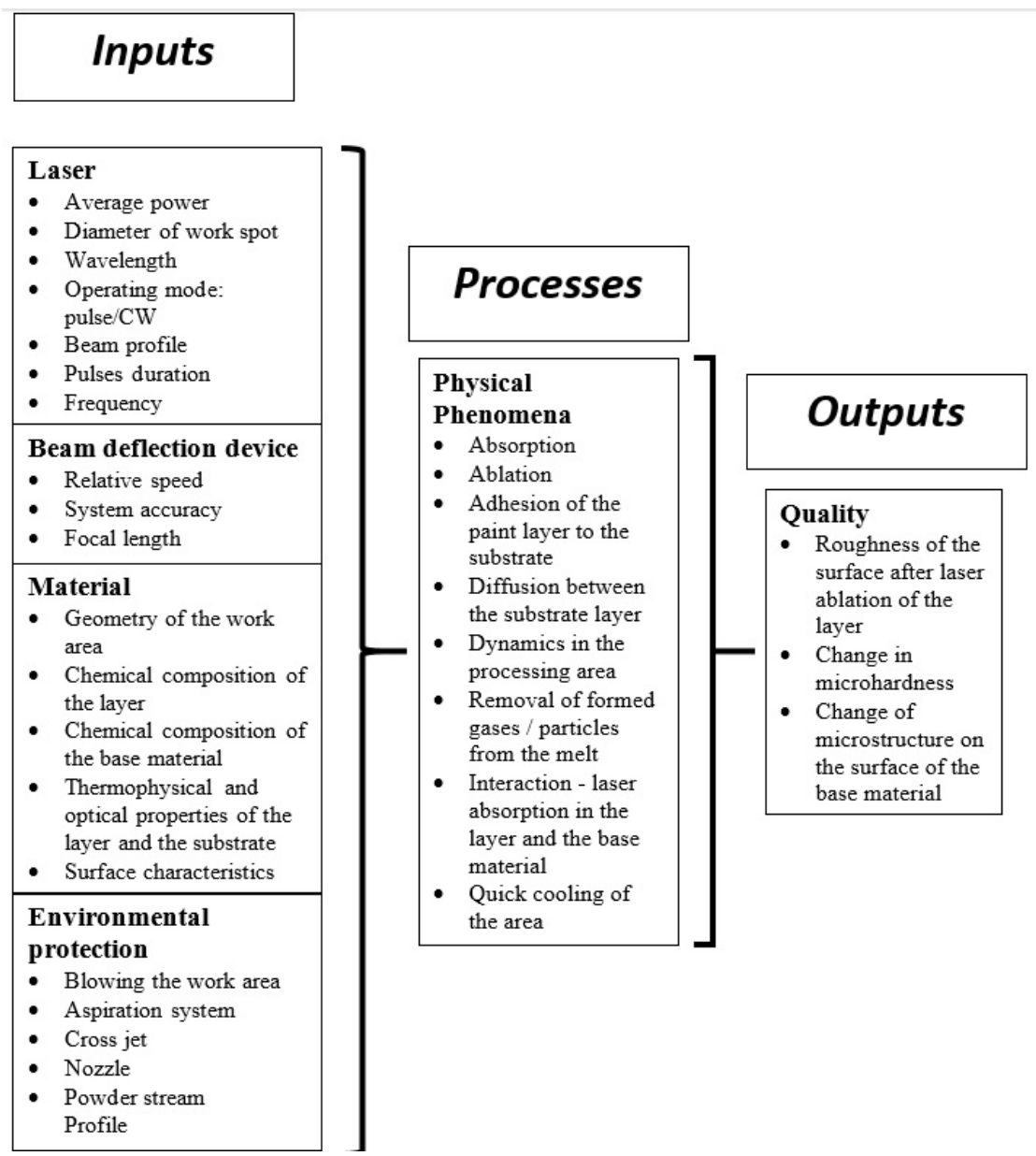

In the publication [2], authors research removal of a thin oxide layer from a tungsten ribbon. They use the fundamental $(\lambda=1064 \mathrm{~nm})$, second $(\lambda=532 \mathrm{~nm})$ and third harmonic $(\lambda=355 \mathrm{~nm})$ radiation from a Q- switched NdYAG laser. It was found that beyond the threshold, oxide removal was achieved at all wavelengths for a wide range of influence values. The removal mechanism of the oxide layer was found to be dependent on both wavelength and influence of the incident radiation and has been identified as ejection or sublimation. The un-cleaned and cleaned surfaces were analyzed by scanning electron microscopy (SEM), energy dispersive X-ray analysis (EDS) and atomic force microscopy (AFM). Laser cleaned tungsten ribbons were used in a thermal ionization mass spectrometer (TIMS) to determine isotopic composition of Neodymium atoms.

In the paper [3], the research about continuous wave (CW) laser cleaning technique is employed to clean the paint on the substrate of aluminum alloy, using in the shipbuilding. The track width and depth of laser ablated craters are measured to study the removal rates. The analysis of $\mathrm{cw}$ laser cleaning is performed to explain the removal process that is theoretically based on the model, created from the authors. The model uses the heat equation with the corresponding initial and boundary conditions. It makes it possible to determine the temperature profile in the area of impact, the thermal stress profiles, the adhesion and the cleaning force. Experimental studies have also been conducted. The sample surfaces are irradiated while utilizing a cw fiber laser. The laser beam spot is perpendicular to the substrate surface and the laser spot size is $5.0 \mathrm{~mm}$. The following results were obtained:

- A relationship between the removal depth rate and the power density for epoxy polyester (EP) coatings;

- $\quad$ The removal rate of the EP paint depending on the output power of the laser;

- $\quad$ The relationship between laser power density and roughness on the cleaned surface;

- The relationship between scanning velocity and the roughness on the cleaned surface; 
- The dependence of HV hardness on the center of the scan line and the upper surface.

The parametric and morphological studies indicate that the cleaned surface of aluminum alloy could be achieved at proper parameters.

In [6], laser cleaningis researched as a proces with significant advantages over the conventional cleaning techniques. It is a well-controlled process with unique properties, such as precise treatment, high selectivity, and high flexi-bility. A cleaning technique using a high-power fibre laser is developed for the surface preparation of steel. Fibre laser has advantages of compact system, automation capability, and low maintenance cost. They report the laser cleaning results using a 500-W pulsed high-power fibre laser. The laser cleaning is able to meet the requirements of the International Organization for Standardization (ISO) standard 8501.

Laser assisted cleaning of oxide films on stainless steel plates is studied both experimentally and theoretically in [1]. The highly oxidized surfaces with oxide scales of about $25 \mathrm{~mm}$ thickness are irradiated with Q-switched pulsed Nd:YAG lasers with and without frequency doubling, i.e., at $1064 \mathrm{~nm}$ and $532 \mathrm{~nm}$ wavelengths. Both multiple irradiation on single spots and scanning with pulsed lasers are employed. The variables studied are laser wavelength, pulse duration, number of pulses, and scanning velocity. Laser cleaning experiments were performed in which the cleaned samples were at rest and in motion. The results indicate that heavily oxidized stainless steel surfaces can be cleaned with short, high power density pulses. Shorter laser wavelength, higher power density, and irradiation with multiple pulses improve the surface cleaning. No loss of the underlying metal layer is observed during treatment.

In the publication [12], the authors show that thermal stress is the main mechanism in the process of paint removal by Q-switched Nd:YAG laser ( $\lambda=1064 \mathrm{~nm}, t=$ $10 \mathrm{~ns}$ ). A theoretical model of paint removal by short-pulse laser is established from the perspective of thermal stress. Thermal stress is generated by thermal expansion, and the temperatures of different samples are calculated according to the one-dimensional heat conduction equation. The theoretical cleaning threshold can be obtained by comparing thermal stress with the adhesion of paint, and the theoretical damage threshold is obtained by calculating the temperature. Moreover, the theoretical calculations are verified by experimental results.

In the paper [16], authors show results of the investigation into the feasibility of using a $\mathrm{CO}_{2}$ laser technology to perform critical cleaning of gas-turbine aero-engine components for manufacture. They report the results of recent trials and relate these to a thermal model of the cleaning mechanisms, and describe resultant component integrity. The paper defines the experimental conditions for the laser cleaning of various aerospace-grade contaminated titanium alloys, using a continuous wave
$\mathrm{CO}_{2}$ laser. Laser cleaning of Ti64 proved successful for electron beam welding, but not for the more sensitive Ti6246. For diffusion bonding the trials produced a defective standard of joint. Effects of oxide formation is modelled and examined experimentally.

The paper [7] investigated the feasibility and the efficiency of removal of rust from the ship steel using $\mathrm{CO}_{2}$ pulsed laser. The results show that $\mathrm{CO}_{2}$ pulsed laser can effectively clean the rust by using suitable parameters without damage the substrate. A cleaning threshold for stripping rust of power density exists. Also, the effect of the process parameters on the efficiency and performance as well as the removal mechanism were studied in this paper.

An investigation in the paint stripping of a single-layer epoxy polyester hybrid coating from an aluminium substrate highly suitable for recycling process is made in [11]. The feasibility of a diode laser source without any assistance of oxygen flow was checked and the best operative conditions were sought. Attention was first paid on the deposition of the polymeric film on aluminium substrates so as to perform the paint stripping process on coatings with the closest geometrical tolerances and dimensional accuracy. Then, a full factorial experimental design was led in order to study the influence of main process variables, that is, the interaction time, the power density, the focusing length, the absorption coefficient and the number of passes on the effectiveness of paint stripping expressed in terms of paint removal depth. Finally, several process maps were developed as a support in identifying the best way to lead the paint stripping process. Process characteristics, leading mechanisms and a simple regression linear model, easily applicable to a wide range of paint stripping contexts, were also discussed in detail.

Experiments to investigate the potential for practical laser graffiti-removal systems are reported in [19]. A universal engineering curve for the time needed for removal of paint from nonconductive substrates that was valid over a range of $10^{7} \mathrm{~W} / \mathrm{cm}^{2}$ in intensity was measured with a variety of lasers. Comparable times were measured for conductive substrates, when pulses shorter than the thermal conduction times were used. The influence of the power, pulse energy, frequency, pulses duration and exposure time has been researched. Analysis suggests that Qswitched Nd:YAG lasers may be the most efficient means for removing graffiti and other unwanted paint. An 1-m2 area of paint $14 \mu \mathrm{m}$ thick can be removed in approximately 10 min with a $50-\mathrm{Hz}$ laser system of $15-\mathrm{W}$ average power.

In the paper [21], the application of laser cleaning in the conservation of cultural assets is reviewed - stone and metal artifacts along with wall and easel paintings. The innovative part is entirely dedicated to the extension of the application perspective of the Nd:YAG lasers by exploiting the significant versatility provided by their different pulse durations. Besides extensively discussing the specific conservation and physical problems involved 
Environment. Technology. Resources. Rezekne, Latvia Proceedings of the $13^{\text {th }}$ International Scientific and Practical Conference. Volume 3, 187-194

in stone and metal cleaning, a significant effort was also made to explore the application potential for wall and easel paintings. The study of the latter was confined to preliminary irradiation tests carried out on prepared samples. The authors characterized the ablation phenomenology, optical properties, and photomechanical generation associated with the irradiation of optically absorbing varnishes using pulse durations of 10 and 120 ns. Further results concern the nature of the well-known problem of the yellowish appearance in stone cleaning, removal of biological growths and graffiti from stones, cleaning of bronze and iron artifacts and related aspects of laser conversion of unstable minerals, removal of calcareous stratification from wall paintings, and other features.

\section{CONCLUSIONS}

In summary, the proposed methods of laser ablation deepen the knowledge of technologists and operators in this field. They can make a choice of suitable technical devices for laser ablation of paint. In addition, they can evaluate the influence of various factors on the laser ablation process. Systematizing these factors makes it easier for them to plan their experiments when working with different paints or laser sources.

\section{REFERENCES}

[1] Guo, H, R. Martukanitz, T. DebRoy, Laser assisted cleaning of oxide films on SUS409 stainless steel, Journal of Laser Applications, 2004, 16(4): 236-244. DOI: https://doi.org/10.2351/1.1809639

[2] Kumar, An., V. Sonar, D. Das, R. Bhatt, P. Behere, M. Afzal, Ar. Kumar, J. Nilaya, D. Biswas, Laser cleaning of tungsten ribbon, Applied Surface Science, 2014, 308: 216-220., DOI: https://doi.org/10.1016/j.apsusc.2014.04.138

[3] Brygo, F., C. Dutouquet, F. Le Guern, R. Oltra, A.Semerok, J. Weulerssea, Laser fluence, repetition rate and pulse duration effects on paint ablation, Applied Surface Science, 2006, 252(6): 21312138. DOI: $10.1016 /$ j.apsusc.2005.02.143

[4] Chen, G., T. Kwee, K. Tan, Y. Choo, M. Hong, Laser cleaning of steel for paint removal, Applied Physics A, 2010, 101(2): 249-253, DOI: https://doi.org/10.1007/s00339-010-5811-0

[5] U.S. Department of the Navy Carderock Division; Naval Surface Warfare Center; Peterson Builders Inc.,The National Shipbuilding Research Program: Surface Preparation and Coating Handbook; IIT Research Institute: Chicago, IL, USA, 1994 https://apps.dtic.mil/sti/pdfs/ADA447625.pdf

[6] Chen, G., T. Kwee; K. Tan, Y. Choo, M. Hong, High-power fibre laser cleaning for green shipbuilding. Journal of Laser Micro / Nanoengineering, 2012, 7(3):249-253. DOI: 10.2961/j1mn.2012.03.0003

[7] Ke, L.; H. Zhu, W. Lei, Z. Cheng, Laser cleaning of rust on ship steel using TEA CO2 pulsed laser. In Photonics and Optoelectronics Meetings (POEM) 2009: Industry Lasers and Applications; International Society for Optics and Photonics: Bellingham,WA, USA, 2009; Volume 7515, 75150G1-75150G8, DOI: $10.1117 / 12.846775$

[8] Madhukar, Y., S. Mullick, D. Shukla, S. Kumar, A. Nath, Effect of laser operating mode in paint removal with a fiber laser, Applied Surface Science, 2013, 264, 892-901, DOI: https://doi.org/10.1016/j.apsusc.2012.10.193

[9] Tsunemi, A., K. Hagiwara, N. Saito, K. Nagasaka, Y. Miyamoto, O. Suto, H. Tashiro, Complete removal of paint from metal surface by ablation with a TEA $\mathrm{CO}_{2}$ laser, Applied Physics A, 1996, 63, 435-439, https://link.springer.com/article/10.1007/BF01571670

[10] Schmidt, M.J.J.; Li, L.; Spencer, J.T. An investigation into the feasibility and characteristics of using a $2.5 \mathrm{~kW}$ high power diode laser for paint stripping, Journal of Materials Processing Technology, 2003, 138, Issues 1-3, 109-115, DOI: https://doi.org/10.1016/S0924-0136(03)00057-8

[11] Barletta, M.; Gisario, A.; Tagliaferri, V. Advance in paint stripping from aluminium substrate, Journal of Materials Processing Technology, 2006, 173, Issue 2, 232-239, DOI: https://doi.org/10.1016/j.jmatprotec.2005.11.029

[12] Zou, W., Y. Xie, X. Xiao, X. Zeng, Y. Luo, Application of thermal stress model to paint removal by Q-switched Nd: YAG laser, Chinese Physics B, Volume 23, Number 7, 074205, 2014, DOI: 10.1088/1674-1056/23/7/074205

[13] Lu, Y.F.; Song,W.D.; Ang, B.W.; Hong, M.H.; Chan, D.S.H.; Low, T.S. A theoretical model for laser removal of particles from solid surfaces, Applied Physics A, 1997, 65, 9-13, DOI: https://doi.org/10.1007/s003390050533

[14] Tam, A., W. Leung, W. Zapka, W. Ziemlich, Laser-cleaning techniques for removal of surface particulates, Journal of Applied Physics, 1992, 71, 3515-3523, DOI: https://doi.org/10.1063/1.350906

[15] Kelley, J.D.; Hovis, F.E. A thermal detachment mechanism for particle removal from surfaces by pulsed laser irradiation, Microelectronic Engineering, 1993, 20 (1-2), 159-170, DOI: https://doi.org/10.1016/0167-9317(93)90213-O

[16] Turner, M., P. Crouse, L. Li, A. Smith, Investigation into $\mathrm{CO}_{2}$ laser cleaning of titanium alloys for gas-turbine component manufacture, Applied Surface Science., 2006, 252 (13), 4798-4802, DOI: https://doi.org/10.1016/j.apsusc.2005.06.061

[17] Gathers, G., Thermophysical properties of liquid copper and aluminum International Journal of Thermophysics, 1983, 4, 209226, DOI: https://doi.org/10.1007/BF00502353

[18] Li, X., T. Huang, W. Chong, R. Zhou, Y. S. Choo, M. Hong, Laser cleaning of steel structure surface for paint removal and repaint adhesion, Opto-Electronic Engineering, 2017, 44(3): 340-344, DOI: 10.3969/j.issn.1003-501X.2017.03.009

[19] Liu, K., E. Garmire, Paint removal using lasers, Applied Optics 34(21):4409-4415, 1995, DOI: 10.1364/AO.34.004409

[20] Razab, M., A. Noor, M. Jaafar, N. Abdullah, F. Suhaimi, M. Mohamed, N. Adam, N. Jusuf, A review of incorporating Nd: YAG laser cleaning principal in automotive industry, Journal of Radiation Research and Applied Sciences, Vol. 11, Issue 4, 2018, DOI: https://doi.org/10.1016/j.jrras.2018.08.002

[21] Siano, S., J. Agresti, I. Cacciari, D. Ciofini, M. Mascalchi, I. Osticioli, A. Mencaglia, Laser cleaning in conservation of stone, metal, and painted artifacts: state of the art and new insights on the use of the Nd: YAG lasers, Applied Physics A, Volume 106, Issue 2, 419-446, 2012, DOI: https://doi.org/10.1007/s00339-011-6690$\underline{8}$

[22] Bergström, D., J. Powell, A. Kaplan, The absorptance of steels to Nd: YLF and Nd: YAG laser light at room temperature, Applied Surface Science Vol. 253 Issue 11 (2007): 5017-5028, DOI: https://doi.org/10.1016/j.apsusc.2006.11.018

[23] Mongelli, G., Portable handheld laser small area supplemental coatings removal system retrieved from Dayton, Ohio, United States, 2005, https://apps.dtic.mil/sti/pdfs/ADA451223.pdf

[24] Laser Paint Stripping, Laser Cleaning and Coating Removal Solutions, Lasertronics.com, General Lasertronics Corporation, www.lasertronics.com/wp/applications/ship-maintenance/

[25] Dichev, D., I. Zhelezarov, T. Karadzhov, N. Madzharov and D. Diakov, "Method for measuring motion parameters of moving objects," 12th International Scientific and Practical Conference on Environment, vol. 3, 27-31, 2019, DOI: 10.17770/etr2019vol3.4131 
[26] G. Cvetanov, T. Karadzhov and R. Miteva, "Determination of the elastic displacements in plain strained condition of involute cylindrical gears with asymmetric profile," in 46th International Conference on Applications of Mathematics in Engineering and Economics, Sofia Bulgaria, 2021. DOI: 10.1063/5.0042511

[27] Zlateva-Petkova, T., Human Resources Quality as a Factor for Competitive Power of Organizations, State University SUMI, vol.
3, pp. 207-212, Ukraine, 2011, ISSN 2218-4511, https://www.researchgate.net/publication/279473856 Human res ources quality as a factor for competitive power of organizati ons 